\title{
A FORMAÇÃO DOCENTE PARA A EDUCAÇÃO PROFISSIONAL E TECNOLÓGICA: BREVE CARACTERIZAÇÃO DO DEBATE
}

\author{
Jair José Maldaner \\ IFTO, Campus Palmas \\ jairmaldaner@yahoo.com.br \\ 10.15628/rbept.2017.5811 \\ Artigo submetido em mar/2017 e aceito em out/2017
}

\section{RESUMO}

Neste texto teceremos algumas considerações sobre a formação de professores na Educação Profissional e Tecnológica - EPT, dando especial destaque à Rede Federal de EPT. Trata-se de parte dos resultados da nossa investigação de doutorado. Percebemos cotidianamente os desafios impostos ao trabalho do professor da rede federal, advindos das mudanças na estrutura e organização do mundo do trabalho e das políticas públicas do governo federal para a EPT. Desafios que requerem do professor uma formação consistente, pois no seu fazer cotidiano lida com as técnicas, as tecnologias, a ciência e precisa transpor isso didaticamente para seus alunos. Precisa ensinar sem ter a formação pedagógica adequada para tal. Diante deste contexto são impostas uma série de demandas para a formação de professores da EPT, tema pouco pesquisado pela academia e poucas vezes objeto das políticas públicas, ao longo da história brasileira. A formação de professores para esta área, no Brasil, sempre foi tratada de forma marginal, aligeirada e imediatista. Esta formação deve ir além da aquisição de técnicas didáticas de transmissão de conteúdos. Deve, por isso, privilegiar uma formação humana mais ampla que vá além daquela que prioriza as relações de mercado.

Palavras-Chaves: Formação de professores, Educação Profissional e Tecnológica, Docência na Educação Profissional e Tecnológica; Trabalho e Educação.

\section{ABSTRACT}

In this text we will expound considerations on the teaching formation of the teachers in the Professional and Technological Education -PTE, highlighting the Rede Federal de EPT. This work represents part of our doctoral research. We noticed in an everyday basis the challenges that are imposed to the labor of the Rede Federal teacher. Those state of affairs derived from the changes in the structure and organization of the world of labor and the federal government political policies for the PTE. The challenges require a sound formation from the teacher, because in his/her day-to-day render deals with the techniques, the technologies, science and has to bridge that didactically to the students. He/she has to teach without an appropriate pedagogical formation.

Given that context, a series of demands are imposed for the PTE teacher formation , a topic that is not often researched by the academy and is seldom the object of the public policies, over the Brazilian history. The teacher training for this area in Brazil has always been treated in an ease, immediate and marginal manner. This training has to go beyond the acquisition of didactic techniques of content transmission. It has to favor a much broader human formation that may go past that one that prioritizes the market relations.

Keywords: Teacher training, Professional and Technological Education, Teaching in the Professional and Technological Education; Work and Education. 


\section{INTRODUÇÃO: CONTEXTO E FUNDAMENTOS DA EPT}

Percebemos cotidianamente os desafios impostos ao trabalho do professor da rede federal, advindos das mudanças na estrutura e organização do mundo do trabalho e das políticas públicas do governo federal para a Educação Profissional e Tecnológica - EPT. Desafios que requerem do professor da EPT uma formação consistente, pois no seu fazer cotidiano lida com as técnicas, as tecnologias, a ciência e precisa transpor isso didaticamente para seus alunos. Precisa ensinar sem que, na maioria dos casos, tenha tido formação pedagógica para tal.

Diante deste contexto e da expansão da rede federal que ocorreu a partir de 2005, são impostas uma série de demandas para a formação de professores da EPT, tema pouco pesquisado pela academia e poucas vezes objeto das políticas públicas, ao longo da história brasileira. A formação de professores para a EPT sempre foi tratada de forma marginal, aligeirada e imediatista.

Entendemos que determinado estágio de desenvolvimento das relações de produção, da qual a organização do mundo do trabalho é consequência, impõe determinado modelo de formação de professores. Este processo exige opções e compromissos que devem ser assumidos pelos formadores de professores da EPT. Em outras palavras, a formação de professores para a EPT não é neutra. Sendo intencional, nas diferentes épocas, mantém um compromisso com um modelo de sociedade, com uma organização societária. Ela pode ter compromissos com o capital ou compromissos com os que vivem do trabalho. Diante desta constatação, Carvalho (2003, p. 17-18) afırma que é preciso compreender as demandas colocadas para a educação profissional no capitalismo contemporâneo e as respostas que ela pode dar, tanto no sentido de uma educação do capital e, portanto, para consolidar a sua hegemonia, ou uma educação do trabalho e, por conseguinte, instrumento de contrahegemonia.

Observamos, assim, que a formação de professores no atual quadro de organização do mundo do trabalho impõe um debate sobre as exigências epistemológicas, políticas e pedagógicas desta formação.

Defendemos que a formação de professores para a EPT, para além da formação técnica no sentido do domínio de conteúdos específicos e formação específica (pedagógica) para se tornar professor, pressupõe um compromisso político para com a classe que vive do próprio trabalho, a classe trabalhadora. Isso porque, de acordo com Carvalho (1989), se, de um lado, a escola e seus profissionais são chamados a responder às exigências do capital, por outro lado, eles participam, ainda que de maneira subordinada, de respostas às necessidades legítimas da classe trabalhadora (CARVALHO, 1989, p. 75). Esta questão requer dos professores, em primeiro lugar, a consciência de que, como educadores, somos assalariados e, portanto, força de trabalho, mercadoria, o que acena para a possibilidade de solidariedade, e em segundo lugar, que somos também intelectuais e só a nossa identificação política, enquanto classe, nos possibilita exercer a nossa função em termos de uma nova hegemonia: a hegemonia proletária (CARVALHO, 1989, p.138).

De acordo com Nóvoa (1999) as políticas de formação de professores padecem de um Excesso dos Discursos e uma Pobreza das Práticas, especificamente do excesso da retórica política e dos mass-media à pobreza das políticas educativas; do excesso das linguagens dos especialistas internacionais à pobreza dos programas de formação de professores; do excesso do discurso científico-educacional à pobreza das práticas pedagógicas; do excesso das "vozes" dos professores à pobreza das práticas associativas docentes (NÓVOA, 1999, p.2). Neste sentido, 
Para pregar o civismo ou para imaginar o futuro, nada melhor do que os professores. É para eles que se viram as atenções dos políticos e da opinião pública quando não encontram outras respostas para os problemas. O excesso dos discursos esconde a pobreza das práticas políticas. Neste fim de século, não se veem surgir propostas coerentes sobre a profissão docente. Bem pelo contrário. As ambiguidades são permanentes. Por um lado, os professores são olhados com desconfiança, acusados de serem profissionais medíocres e de terem uma formação deficiente; por outro lado, são bombardeados com uma retórica cada vez mais abundante que os considera elementos essenciais para a melhoria da qualidade do ensino e para o progresso social e cultural (NÓVOA, 1999, pp.2-3).

Estas observações de Nóvoa confirmam a centralidade e importância da formação docente no estabelecimento de políticas públicas em educação. Em nível macro as demandas de formação de professores respondem a configurações que se originam nas mudanças ocorridas no mundo do trabalho e nas relações sociais.

Em relação à discussão em torno do currículo e dos objetivos da educação na sociedade capitalista, Franco nos indica ainda que,

O predomínio da ideologia dos valores de mercado da produção capitalista na educação introduziu uma nova divisão, separando as humanidades das ciências e das tecnologias, hierarquizando as últimas, ora como alto desenvolvimento científico e tecnológico, ora como necessidade estrita de operação nas empresas de indústria e serviços. Essa concepção viesada pelos interesses produtivos conduziu, frequentemente, os professores ao exercício do pragmatismo, em que educar é preparar para o trabalho segundo as necessidades do mercado de trabalho, supondo-se que haveria empregos para todos. O mito da empregabilidade, a "promessa emancipadora" da sociedade moderna industrial, há mais de uma década, estão sendo desmentidos pela introdução de alta tecnologia com base na informática, na microeletrônica e pela nova organização do trabalho (FRANCO, 2008, p. 49).

Com o sentido de resistência à educação adaptativa, a matriz crítico-emancipatória de educação tem seus fundamentos no pensamento crítico e dialético e pretende ressignificar a noção de competência, atribuindo-lhe um sentido que atenda aos interesses dos trabalhadores, bem como, apontar princípios orientadores para a investigação dos processos de trabalho, para a organização do currículo e para uma proposta de educação profissional ampliada.

Esta concepção de competências e de currículo, que está em processo de discussão e disputa na educação brasileira, defende que a organização curricular deve ter em conta que: a) a realidade é uma totalidade em que estão presentes os aspectos econômicos, políticos, históricos, culturais, científicos, técnico-operacionais, ambientais; $b$ ) o ser humano atua sobre a natureza e sobre a sociedade a que pertence em situação social e não apenas individual; c) é nesse processo que ocorre a objetivação de bens, produtos e serviços e a subjetivação do próprio produtor; d) a aprendizagem significativa supõe que os conteúdos devem ser contextualizados, e a realidade deve ser pensada criticamente além do senso comum; e) a simples opção metodológica não dá conta de todas as implicações históricas e epistemológicas 
do conhecimento secularmente acumulado pela humanidade; f) na educação ocorre um processo contínuo de apropriação, objetivação e subjetivação dos conteúdos disciplinares em relação íntima com os métodos e processos utilizados. Em síntese, trata-se de alcançar uma outra qualidade da educação que se inicia pela formação e adesão do professor (FRANCO, 2008, p. 50-51).

Nesta mesma perspectiva Carvalho afirma:

A profunda mudança na organização econômica, social e cultural dos países envolvidos no processo de globalização, que assistimos desde a década de 1970, obriga-nos a repensar as políticas e os sistemas de ação no campo da educação profissional. O mundo do trabalho mudou e a educação profissional tem desafios novos, embora, no Brasil, ainda não tenham sido superados velhos desafios. Como uma área tão desprestigiada historicamente pode assumir o protagonismo requerido pelas transformações atuais no mundo do trabalho? (CARVALHO, 2008, p.150).

De acordo com Carvalho (2008), dois elementos são fundamentais no desenvolvimento dessa nova formação. O primeiro diz respeito ao reconhecimento de que sem uma formação básica de qualidade os jovens não conseguem compreender as mudanças da economia e da sociedade, tão pouco participar criticamente dessas mudanças. Isso implica em educação profissional colada com a educação básica. 0 segundo elemento se refere à necessidade de um reforço na formação contínua, visto que as transformações na sociedade atual evidenciam uma relação entre trabalho e educação, na qual integração econômica e social dos indivíduos supõe a ampliação do nível de formação em todos os setores sociais. 0 desafio agora, de acordo com Carvalho,

é o de aprofundar a discussão prevenindo e reduzindo as vulnerabilidades geradas por uma globalização excludente, sem, no entanto, transformar a educação profissional numa panacéia, encarando-a, ao contrário, como uma condição necessária, mas não suficiente para o êxito dos processos de reestruturação produtiva em curso (CARVALHO, 2008, p. 151).

Desta forma, "é preciso superar a profissionalização estreita que reduz a formação profissional à aquisição do saber fazer, ampliando-a para uma formação profissional com uma sólida formação geral e uma significativa cultura científica e tecnológica" (CARVALHO, 2008, p.153).

Enfim, todas as questões levantadas sinalizam que a formação profissional e tecnológica deve ser mais abrangente.

Preparar para o trabalho não significa apenas preparar para exercer funções específicas, mas significa, sobretudo, compreender a sociedade naquilo que é estruturante dela, ou seja, o trabalho. A formação profissional deve desempenhar um papel para além dos limites impostos de forma artificial pelo mercado de trabalho, devendo ser encarada como um imperativo de vida em sociedade, como um direito e como um dever de cada cidadão (CARVALHO, 2008, p. 154). 
Desta forma, as mudanças ocorridas no mundo do trabalho e nas relações sociais apontam na direção deuma formação deprofessores mais rigorosa,com sólidosfundamentos gerais, comum a todos os professores da educação básica, a ser complementada, no caso dos professores dos conteúdos específicos de educação profissional integrada ao ensino médio, com conhecimentos e práticas científico-tecnológicas e sócio históricas da área de trabalho a ser ensinada (KUENZER, 1999).

Machado (2008a) afirma que a formação de professores para a EPT atende a um profissional que sabe o que, como e porque fazer e que aprendeu a ensinar, para desenvolver idônea e adequadamente outros profissionais.

\section{SABERES DOS PROFESSORES, NOVO PERFIL E AS ESPECIFICIDADES DA FORMAÇÃO DE PROFESSORES PARA A EPT}

De acordo com Gariglio e Burnier ,a docência na EPT é constituída de saberes:

Se compreendermos que o exercício docente na EP constituiu um ofício feito de saberes, o desafio da profissionalização desses professores deve motivar-nos a investigar os saberes próprios do ensino, sendo necessária, para isso, a produção de estudos que consigam revelar as singularidades do contexto profissional no qual os professores encontram-se mergulhados. Os esforços de diversos estudiosos em definir os conteúdos dos saberes da base profissional dos professores ainda trazem consigo indefinições sobre o conceito de "saber". Surgem estes questionamentos: os professores desenvolvem e/ou produzem verdadeiramente "saberes" resultantes de sua prática? Caso positivo, quando, como, sob que forma? Tratam-se verdadeiramente de saberes? Não seriam antes crenças, certezas não fundamentadas ou habitus, esquemas de ação e de pensamento interiozados no âmbito da socialização profissional? (GARIGLIO; BURNIER, 2012, p.4).

Se o ofício docente é feito de saberes, o desafio da profissionalização dos docentes da EPT deve motivar-nos a investigar quais seriam os saberes da base profissional desses professores, sendo necessária, para isso, a produção de estudos que consigam revelar as características desses saberes, bem como o complexo contexto de trabalho no qual esses professores encontram-se mergulhados (GARIGLIO; BURNIER, 2012, p.5).

Fartes e Santos (2011), tratando sobre o tema da docência em EPT, se perguntam como:

Tratar da docência na EPT, área que, ao mesmo tempo em que compartilhaproblemas gerais daformaçãodocente, trazdiferenciações nada desprezáveis em relação aos demais docentes de outros níveis e modalidades de ensino; enfrentar esse desafio, a começar pelo fato de que a educação profissional e tecnológica está mais diretamente exposta às exigências dos setores produtivos e das constantes regulações nas políticas curriculares, além do que uma boa parcela de seus docentes, por ter formação superior nas áreas técnicas, não se identifica como professor, além de não trazer em sua bagagem curricular os aportes necessários à reflexão pedagógica; pensar a 
docência em meio à diversificação desse público, constituído por graduados (bacharéis e/ou tecnólogos) originários de áreas técnicas, sem formação para o magistério, e por licenciados para disciplinas da educação básica sem a formação que Ihes permita articular as relações entre o mundo do trabalho e a educação profissional (FARTES e SANTOS, 2011, p.2).

A complexidade da sociedade contemporânea, as metamorfoses do mundo do trabalho, a presença das tecnologias no cotidiano das pessoas implicam determinado perfil dos docentes da educação profissional. Para Machado (2008a, p. 15), não é mais suficiente o padrão do artesanato, quando o mestre da oficina-escola se apresentava como o espelho que o aluno praticante deveria adotar como referência. 0 padrão da escola oficina, que impunha ao aluno a aplicação de séries metódicas de aprendizagem também está superado. Instrutores recrutados nas empresas, segundo o padrão de que para ensinar basta saber fazer, apresentam grandes limitações não somente pedagógicas, mas também teóricas com relação às atividades práticas que ensinam.

De acordo com Kuenzer, (1998), o que confere especificidade à função do educador é a compreensão histórica dos processos pedagógicos, a produção teórica e a organização de práticas pedagógicas, para o que usará da economia sem ser economista, da sociologia sem ser sociólogo, da história, sem ser historiador, posto que seu objeto são os processos educativos historicamente determinados pelas dimensões econômicas e sociais que marcam cada época. Esta dimensão formativa precisa ser resgatada dadas as atuais características da produção pedagógica contemporânea. Esta,

(...) de modo geral, tem se dividido: de um lado, aquela que vai ao mundo do trabalho e das relações sociais para compreender os processos educativos escolares e não-escolares e não faz o caminho de retorno, caracterizando-se por macro análises, que, embora relevantes e necessárias, não contribuem para a organização de projetos e práticas pedagógicas que respondam, no sentido de atender e superar, às atuais demandas por educação feitas por estas relações mais amplas, perpassadas pela contradição fundamental do modo capitalista de produção de mercadorias. De outro, aquela que não sai do espaço restrito das organizações e práticas pedagógicas, tratando-as como se fossem autônomas, e até determinantes, daquelas relações sociais (KUENZER, 1998, p.2).

Neste sentido, quais são as especificidades da educação profissional? No que elas implicam na formação de professores para esta área? Concordamos com Machado quando a autora afirma que a educação profissional tem no seu objeto de estudo e intervenção sua primeira especificidade, a tecnologia. Esta, por sua vez, se configura como uma ciência transdisciplinar das atividades humanas de produção, do uso dos objetos técnicos e dos fatos tecnológicos. Do ponto de vista escolar, é disciplina que estuda o trabalho humano e suas relações com os processos técnicos (MACHADO, 2008a, p. 16).

É próprio do ensinar-aprender tecnologia e, portanto, da docência na educação profissional tratar da intervenção humana na reorganização do mundo físico e social e das contradições inerentes a esses processos, exigindo discutir questões relacionadas às necessidades sociais e às alternativas tecnológicas (MACHADO, 2008a, p. 16). 
Na Rede Federal de EPT a atuação do professor é muito diversa, inclui: os programas de formação inicial e continuada de trabalhadores; o ensino técnico nas formas concomitante, subsequente e integrado ao ensino médio; as variantes da formação inicial e continuada e do ensino técnico quando ministradas de forma articulada com a educação de jovens e adultos; a graduação nos Cursos Superiores de Tecnologia - CSTs, bacharelados, licenciaturas e a pós-graduação. De acordo com Machado (2008a, p. 17), dada esta diversidade de situações os professores da educação profissional são levados a atuar com um mínimo de orientações pedagógicas e técnicas. Com isso, o trabalho de transposição didática é realizado geralmente sem qualquer avaliação externa.

Entende-se que o professor da EPT é um profissional que sabe o que, como e porque fazer e que aprendeu a ensinar, para desenvolver idônea e adequadamente outros profissionais. Desta forma, tem papel e compromisso como educador, independentemente de outra atividade que venha a ter, contribuindo, assim, como participante ativo, para o desenvolvimento da educação profissional.

No seu exercício o professor da EPT deve ser capaz de permitir que seus alunos compreendam, de forma reflexiva e crítica, os mundos do trabalho, dos objetos e dos sistemas tecnológicos dentro dos quais estes evoluem; as motivações e interferências das organizações sociais pelas quais e para as quais estes objetos e sistemas foram criados e existem; a evolução do mundo natural e social do ponto de vista das relações humanas com o progresso tecnológico; como os produtos e processos tecnológicos são concebidos, fabricados e como podem ser utilizados; métodos de trabalho dos ambientes tecnológicos e das organizações de trabalho. Precisa saber desenvolver comportamentos proativos e socialmente responsáveis com relação à produção, distribuição e consumo da tecnologia

Em síntese, o perfil do docente da educação profissional precisa dar conta de três níveis de complexidade: a) desenvolver capacidades de usar, nível mais elementar relacionado à aplicação dos conhecimentos e ao emprego de habilidades instrumentais; b) desenvolver capacidades de produzir, que requer o uso de conhecimentos e habilidades necessários à concepção e execução de objetivos para os quais as soluções tecnológicas existem e devem ser adaptadas; e c) desenvolver capacidades de inovar, nível mais elevado de complexidade relacionado às exigências do processo de geração de novos conhecimentos e novas soluções tecnológicas (MACHADO, 2008a, p. 18).

Além das questões didático-político-pedagógicas, a formação para a docência na EPT deve incluir a discussão relativa à função social da EPT em geral e de cada instituição em particular. Para Moura (2008), podemos sintetizar alguns eixos da formação docente que devem estar presentes em quaisquer das possibilidades de formação apresentadas:

Formação didático-político-pedagógica; uma área de conhecimentos específicos; e diálogo constante de ambas com a sociedade em geral e com o mundo do trabalho. Tais eixos devem contemplar (SANTOS, 2004): as relações entre Estado, sociedade, ciência, tecnologia, trabalho, cultura, ser humano e educação; políticas públicas e, sobretudo, educacionais; papel dos profissionais da educação, em geral, e da EPT, em particular; concepção da unidade ensino-pesquisa; concepção de docência que se sustente numa base humanista; concepção de docência que impregne a prática desse 
profissional quando sua atuação se dá no mundo do trabalho; a profissionalização do docente da EPT: formação inicial e continuada, carreira, remuneração e condições de trabalho; e desenvolvimento local e inovação (MOURA, 2008, p. 36).

A EPT está mergulhada no mundo do trabalho e no mundo das tecnologias. Neste sentido, de acordo com Kuenzer (1999), as mudanças ocorridas no mundo do trabalho e das relações sociais apontam na direção de uma formação docente mais rigorosa, com sólidos fundamentos gerais, comum a todos os professores da educação básica, a ser complementada, no caso dos professores dos conteúdos específicos de educação profissional, com conhecimentos e práticas científico-tecnológicas e sócio históricas da área de trabalho a ser ensinada. Para tanto, a formação deverá contemplar os seguintes eixos:

Contextual, articulando os conhecimentos sobre educação, economia, política e sociedade, e suas relações, tomadas em seu desenvolvimento histórico;

Epistemológico, integrando as teorias e princípios que regem a produção social do conhecimento;

Institucional, contemplando as formas de organização dos espaços e processos educativos escolares e não escolares;

Pedagógico, integrando os conhecimentos relativos a teorias e práticas pedagógicas, gerais e específicas, incluindo cognição, aprendizagem e desenvolvimento humano;

Práxico, de modo a integrar conhecimento científico, conhecimento tácito e prática social;

Ético, compreendendo as finalidades e responsabilidades sociais e individuais no campo da educação, em sua relação com a construção de relações sociais e produtivas, segundo os princípios da solidariedade, da democracia e da justiça social;

Investigativo, comprometido com o desenvolvimento das competências em pesquisa, tendo em vista o avanço conceitual na área do trabalho e da educação (KUENZER, 1999).

Assim, conforme Kuenzer (1999, p. 10-11), a primeira dimensão a ser considerada na formação do professor comprometido com o campo do trabalho é a capacidade de, apoiando-se nas ciências humanas, sociais e econômicas, compreender as mudanças ocorridas no mundo do trabalho, construindo categorias de análise que lhe permitam apreender as dimensões pedagógicas presentes nas relações sociais e produtivas, de modo a identificar as novas demandas deeducação ea que interesses elas se vinculam. Ou seja, compreenderhistoricamente os processos de formação humana em suas articulações com a vida social e produtiva, as teorias e os processos pedagógicos, de modo a ser capaz de produzir conhecimento em educação e intervir de maneira competente nos processos pedagógicos amplos e específicos, institucionais e não institucionais, com base em uma determinada concepção de sociedade.

Para Machado (2011), várias são as questões inerentes ao desafio atual da formação inicial e continuada de professores para a EPT no Brasil. A título de síntese, ela destaca sete urgências, que aqui colocamos de maneira resumida: 
1. Garantir a sustentabilidade pedagógica e de gestão à expansão, interiorização e democratização da oferta de cursos técnicos e de formação inicial e continuada - com destaque para as modalidades ensino médio integrado, proeja, à distância, EPT inclusiva, EPT do campo, indígena e quilombola - urgências que emergem da enorme expansão da Rede Federal de Educação Profissional, Científica e Tecnológica, iniciada em 2005, e das elevadas metas previstas pelo Programa Nacional de Acesso ao Ensino Técnico e EmpregoPronatec e pelo Plano Nacional de Educação - PNE 2011-2020. (MACHADO, 2011, p. 701).

2. Revogar os instrumentos legais que possibilitam autorizações do exercício, a título precário, da função de professor na educação básica.

3. Revogar a Resolução CNE/CP n. 2/97 e regulamentar a oferta de licenciaturas para a EPT com os formatos que compatibilizem especificidades de trajetórias acadêmicas do professorado, observando-se em todos eles os princípios que orientam a base comum de organização curricular dos cursos de formação dos profissionais da educação no Brasil e a perspectiva de uma política nacional unitária de magistério.

4. Oferecer licenciatura a um grande número de professores sem a habilitação requerida pelo artigo 62 da Lei n. 9394/96, que estão em atividade na EPT.

5. Continuar, aprofundar e expandir a política de formação continuada de apoio ao proeja e, nos seus moldes, desenvolver ações semelhantes voltadas ao ensino médio integrado regular, às especificidades da EPT por eixos tecnológicos, à organização curricular por núcleos politécnicos comuns, à EPT a distância, à EPT do campo, à EPT de povos indígenas, à EPT de comunidades quilombolas, à EPT inclusiva (Programa Tecnep).

6. Promover pesquisas e a produção de conhecimentos no campo da EPT, sobretudo com a participação dos próprios professores a ela dedicados (MACHADO, 2011, p. 702).

7. Promover o fortalecimento da identidade profissional dos professores da EPT por meio de políticas de formação, valorização e carreira docente, que levem à diminuição da grande heterogeneidade desse professorado, fator que dificulta seu processo de profissionalização. Estimular o conhecimento por parte dos professores dos determinantes internos e externos à sua atuação profissional, das condições da sua materialidade, das crenças e valores em disputa, dos diferentes saberes que precisam convocar, das especificidades da profissão, das necessidades do desenvolvimento profissional e de como fomentá-lo. (MACHADO, 2011, p. 702-703)

Neste sentido, a formação e profissionalização do educador na perspectiva da práxis têm, como pré-condições, a efetivação de um processo educativo centrado num projeto explícito e consciente no qual as dimensões ético-políticas, teóricas e epistemológicas, acima assinaladas constituam a sua base. Nas condições objetivas das relações sociais capitalistas, dentro das quais atuamos, esta perspectiva contra hegemônica é, sobretudo hoje, considerada um devaneio. Para Frigotto (1996, p. 100-101), o desafio que se coloca é o de vencer a pedagogia da desesperança, e da falta de alternativa ao status quo. Por fim, cabe ressaltar que os elementos formativos e de qualificação do educador pressupõem, mas transcendem a competência técnica e científica adquirida em instituições especializadas e na experiência profissional. A qualificação para o educador também implica a capacitação para ser dirigente. 
Este projeto alternativo, para o qual buscamos nos capacitar como educadores, centra-se na ideia de que, em primeiro lugar, vêm as pessoas e estas não podem ser sacrificadas em nome da reestruturação produtiva. Ou seja, um projeto de uma sociedade centrada na solidariedade e igualdade dos seres humanos. Solidariedade e igualdade que somente podem ser garantidas no espaço público. A luta pela ampliação da esfera pública e pelo controle e manejo democráticos do fundo público, assinalam a direção do socialismo necessário e possível. E hoje, nas nossas lutas concretas, socialismo significa vida garantida: o direito à educação livre e a cuidados de saúde; o direito à comunidade e à associação; o direito ao trabalho (questão nada irrelevante perante as condições endémicas do desemprego pós-moderno) e o direito ao lazer, à cultura e à aposentadoria (Jameson citado por Frigotto, 1996, p. 101).

Concordamos ainda com Frigotto no sentido de que o mundo do trabalho,

(...) como tarefa imperativa da produção e reprodução do ser humano enquanto ser biológico, dentro de um determinado avanço (tecnológico) das forças produtivas, é um espaço crucial, mas não o único, da materialidade das possibilidades e dos limites da formação humana. O trabalho, enquanto valor de uso, manifestação de vida, é um princípio educativo fundamental a ser socializado desde a infância. Todavia, o trabalho, como valor de troca, sob as relações capitalistas ou, anterior a elas, relações escravocratas e servis, é, para a grande massa de trabalhadores, um tormento e um processo alienador (FRIGOTTO, 1996, p. 93).

Os ataques contra esta formação teórico-epistemológica se deram de diversas formas na história brasileira. De acordo com Frigotto (1996), a segregação dos cursos de formação, e das próprias licenciaturas, de uma compreensão sócio histórica, filosófica, política e cultural, resultante da Reforma Universitária de 68, demarca um primeiro e profundo golpe para esta base teórica e epistemológica na formação e profissionalização do educador. Esta decapitação deriva da imposição de uma perspectiva economicista e tecnocrática dos processos de conhecimento e dos processos educativos, amparados pelo golpe civilmilitar de 1964. O segundo golpe dá-se na década de 1990 pela reiteração da concepção produtivista e mercadológica do conhecimento mediante o ajuste neoliberal à globalização excludente, capitaneada pelo Banco Mundial. Hoje, esta perspectiva mercadológica está encarnada no desenvolvimento do Pronatec.

Cabe registrar também que uma política de formação de professores só tem sentido quando integrada à estruturação da carreira docente, à politica salarial que assegure a dignidade do professor e à garantia de condições adequadas de trabalho (KUENZER, 2011, p.4).

Portanto, é preciso reconhecer que a docência na EPT é muito mais que mera transmissão de conhecimentos empíricos ou processo de ensino de conteúdos fragmentados e esvaziados teoricamente. 
Para formar a força de trabalho requerida pela dinâmica tecnológica que se dissemina mundialmente, é preciso um outro perfil de docente capaz de desenvolver pedagogias do trabalho independente e criativo, construir a autonomia progressiva dos alunos e participar de projetos interdisciplinares. Uma política definida para a formação de professores que atenda a tais necessidades será certamente um grande estímulo para a superação da atual debilidade teórica e prática deste campo educacional com relação aos aspectos pedagógicos e didáticos. (MACHADO, 2008a, p. 15).

Assim, para o professor da EPT é basilar a compreensão, teoricamente fundamentada, da dimensão ontológica na conformação das subjetividades, a partir do significado do trabalho no modo de produção capitalista.

\section{CONCLUSÃO: PARA UMA POLÍTICA DE FORMAÇÃO DE PROFESSORES DA EPT}

De acordo com Machado (2008b, p.82), é preciso definir uma política nacional ampla de valorização da formação dos professores para a EPT e que isso passa pela superação de fato da tendência histórica às improvisações, pela institucionalização dessa formação, superação de preconceitos e real tratamento de equivalência formativa comparativamente à recebida pelos demais professores. Para ela, há de fato especificidades nesta área que precisam ser consideradas, mas por que continuar com o adjetivo especial? Se há necessidade de contar com vias diferentes de formação docente para a educação profissional, é preciso denominá-las pelo que eles têm de objetivo e alvo. Outra coisa é essa questão de dar prazos para acatar definições legais. A experiência histórica, nesse caso, mostrou que isso só serviu para protelar as decisões e ações (MACHADO, 2008b, p. 82).

0 debate sobre formação de professores para a EPT exige que se reflita sobre 0 modelo de desenvolvimento socioeconômico do país e o papel da EPT diante desse modelo societário. De acordo com Moura (2008) isso se traduz nas seguintes questões: Formação de professores para que sociedade? Formação de professores para que educação profissional e tecnológica?

Para Moura (2008, p. 31), a formação de professores para a EPT fundamenta-se em dois eixos. 0 primeiro está relacionado com a área de conhecimento específica, adquirida na graduação, cujo aprofundamento é estratégico e deve ocorrer por meio dos programas de pós-graduação, principalmente stricto sensu. 0 outro eixo refere-se à formação didáticopolítico-pedagógica e às especificidades das áreas de formação profissional que compõem a esfera da EPT.

No caso brasileiro, tanto a EPT como os cursos superiores formam profissionais que são formados por profissionais que atuam como professores, embora, na maioria das vezes, não tenham formação específica para esse fim. Enquanto um médico para exercer a profissão precisa da correspondente formação profissional, para exercer o magistério,

existe um conjunto de saberes inerentes à profissão docente que a justifiquem como tal? Se a resposta for sim, temos que fazer outra pergunta: por que, então, existe uma grande liberalidade no mundo do trabalho e na sociedade em geral no sentido de que outrosprofissionaisquenãotêmaformaçãodocenteatuemcomotal? Nossaresposta é: apesar de existir um conjunto de saberes próprios da profissão docente (VEIGA, 2002), essa não tem reconhecimento social e do mundo do trabalho compatível com sua importância para a sociedade, por isso não há esserigor (MOURA, 2008, p. 31). 
Defendemos neste trabalho, corroborando com Machado (2011), que a formação de professores para a EPT é decisiva para que a atual política de expansão, interiorização e democratização dessa modalidade educacional se efetive. Segundo Machado este é um desafio, já histórico, mas que

(...) revela-se mais crítico face à atual expansão da Rede Federal de Educação, Científica e Tecnológica a partir de 2005; às metas do Programa Nacional de Acesso ao Ensino Técnico e Emprego (Pronatec) e Plano Nacional de Educação (PNE) 2011-2020; às novas necessidades político-pedagógicas vindas com o Programa Nacional de Integração da Educação Profissional à Educação Básica na Modalidade de Educação de Jovens e Adultos (Proeja), o Ensino Médio Integrado, Escola Técnica Aberta do Brasil (E-tec), Programa Educação, Tecnologia e Profissionalização para Alunos com Necessidades Educacionais Especiais (Tecnep), EPT indígena e EPT quilombola (MACHADO, 2011, p. 690).

No Brasil, de acordo com Machado (2011, p. 691), ainda se recrutam professores para a EPT fiando-se apenas em formação específica e experiência prática, crendo que a constituição da docência se dará pelo autodidatismo. Contudo, a Lei n. 9.394/96, artigo 62, nos indica que "a formação de docentes para atuar na educação básica far-se-á em nível superior, em curso de licenciatura, de graduação plena, em universidades e institutos superiores de educação (...)" (Brasil, 1996). E, os cursos de educação profissional técnica de nível médio (EPTNM) e os de formação inicial e continuada (FIC) fazem parte da educação básica.

Machado (2011) traz dados importantes sobre a atividade dos professores da EPT que constam da Sinopse do Professor de 2009. Constatou-se 58.898 professores em atividade na educação profissional técnica de nível médio. Destes, apenas 59,0\% possuíam licenciatura; $11,8 \%$ sem curso superior concluído; $11,7 \%$ com somente o ensino médio e $0,07 \%$, o ensino fundamental. Mais da metade (33.100 ou 56,2\%) dos 58.898 professores em atividade na EPTNM tinha vínculo apenas com instituições privadas, rede que se destaca pela grande heterogeneidade de situações e condições de trabalho; 16.943 (28,8\%) professores ligados somente a instituições estaduais, também com grandes diversidades institucionais e contratuais; $6.453(11,0 \%)$ docentes (com atuação na EPTNM) contratados exclusivamente pela rede federal de educação profissional, científica e tecnológica, um universo mais homogêneo, mas que também tem suas clivagens (BRASIL, 2009 citado por MACHADO, 2011, p. 691-692).

Segundo Machado (2011), os objetivos do Pronatec são expandir, interiorizar e democratizar a oferta de cursos técnicos e de formação inicial e continuada, beneficiando oito milhões de estudantes e trabalhadores até 2014. Este processo está em pleno desenvolvimento. Neste sentido cabe questionar: sem uma política de formação de professores para a EPT, de expressividade correspondente, tais objetivos se efetivarão?

O texto do Projeto de Lei n. 1.209/11 e a posterior Lei 12513/11 que institui o Pronatec, não se referem à questão da formação de professores. 
O foco do documento se dirige à ampliação de vagas e das oportunidades educacionais dos trabalhadores mediante a oferta de bolsa-formação; à assistência e transferência de recursos financeiros às instituições de EPT das redes públicas estaduais e municipais, ou dos serviços nacionais de aprendizagem correspondentes aos valores das bolsas-formação e à melhoria da rede física e expansão da rede federal. É possível que a formação de professores para a EPT esteja subentendida nas pretensões do programa de apoio técnico e de melhoria da qualidade do ensino médio público, mas o texto não faz esse esclarecimento (MACHADO, 2011, p. 694-695).

Contraditoriamente, de acordo com Machado, a Setec/Mec vem incentivando as Instituições Federais a desenvolver licenciaturas para a EPT tendo como referências: educação como direito e afırmação de um projeto societário de emancipação social; compromisso com a escola pública; conexões entre a formação de professores para a educação básica e a formação de professores para a educação profissional; diálogo com as políticas sociais e econômicas, com destaque para aquelas com enfoques locais e regionais; incorporação dos princípios educativos do trabalho, da ciência, da tecnologia e da cultura e suas interações; integração entre ensino, pesquisa e extensão; sintonia com as demandas sociais, econômicas e culturais; incorporação da diversidade cultural; sustentabilidade ambiental; ética da responsabilidade e do cuidado; o professor como pesquisador de sua própria prática pedagógica (MACHADO, 2011, p. 699). Todavia, o que predomina nos Institutos Federais é a oferta de licenciaturas para a educação básica e não para a EPT.

\section{REFERÊNCIAS}

1. CARVALHO, Olgamir Francisco de. A Escola como Mercado de Trabalho: Os bastidores da divisão do trabalho no âmbito escolar. São Paulo, Iglu. 1989.

2. Editora, 2003. Educação e Formação Profissional: Trabalho e tempo livre. Brasília: Plano

3. Tendências da relação trabalho/educação no contexto da globalização. In Formação deProfessores para Educação Profissional eTecnológica: Brasília, 26, 27e 28 de setembro de 2006. - Brasília: Instituto Nacional de Estudos e Pesquisas Educacionais Anísio Teixeira, 2008. 304 p. - (Coleção Educação Superior em Debate ; v. 8).

4. FARTES, Vera; SANTOS, Adriana Paula Q. Oliveira. Saberes, identidades, autonomia na cultura docente da educação profissional e tecnológica. Cad. Pesquisa. São Paulo, v. 41, n. 143, Aug. 2011.

5. FRANCO, Maria Ciavatta. A formação de professores para a Educação Profissional e Tecnológica: perspectiva histórica e desafios contemporâneos. In Formação de Professores para Educação Profissional e Tecnológica : Brasília, 26, 27 e 28 de setembro de 2006. - Brasília: Instituto Nacional de Estudos e Pesquisas Educacionais Anísio Teixeira, 2008. 304 p. - (Coleção Educação Superior em Debate ; v. 8).

6. FRIGOTTO, Gaudêncio. A formação e profissionalização do educador: novos desafios. Coletânea da CNTE, 1996, Mimeo.

7. GARIGLIO, José Ângelo; BURNIER, Suzana. Saberes da docência na educação profissional e tecnológica: um estudo sobre o olhar dos professores. Educ. rev., Belo Horizonte, v. 28, n. 1, Mar. 2012. 
8. KUENZER, Acacia Z.

A formação de educadores no contexto das mudanças no mundo do trabalho: Novos desafios para as faculdades de educação. Educ. Soc. vol. 19 n. 63 Campinas Aug. 1998.

9.

.A formação de professores para o Ensino Médio: velhos problemas, novos desafios. Educ. Soc., Campinas, v. 32, n. 116, Sept. 2011.

10. As políticas de formação: A constituição da identidade do professor sobrante, Educ. Soc. vol.20 n.68 Campinas Dec. 1999.

11. MACHADO, Lucília Regina de Souza. Diferenciais inovadores na formação de professores para a educação profissional. Revista Brasileira de Educação Profissional e Tecnológica/Ministério da Educação, Secretaria da Educação Profissional e Tecnológica. V.1, nº 1(jun.2008). Brasília: MEC, SETEC, 2008a. Anual.

12. A formação de professores para a Educação Profissional e Tecnológica: perspectiva histórica e desafios contemporâneos. In Formação de Professores para Educação Profissional e Tecnológica : Brasília, 26, 27 e 28 de setembro de 2006. - Brasília: Instituto Nacional de Estudos e Pesquisas Educacionais Anísio Teixeira, 2008b. 304 p. (Coleção Educação Superior em Debate ; v. 8).

13. O desafio da formação dos professores para a EPT e PROEJA. Educ. Soc., Campinas, v. 32, n. 116, Sept. 2011.

MOURA, Dante Enrique. A formação de docentes para a educação profissional e tecnológica. Revista Brasileira de Educação Profissional e Tecnológica/Ministério da Educação, Secretaria da Educação Profissional e Tecnológica. V.1, n 1(jun.2008).-Brasília: MEC, SETEC, 2008. Anual.

14. NÓVOA, Antônio. Os Professores na Virada do Milênio : do excesso dos discursos à pobreza das práticas. Educ. Pesqui. vol.25 no.1 São Paulo Jan./Jun, 1999. Disponível em < http://dx.doi.org/10.1590/S1517-97021999000100002> acesso em 24 nov. 2013. 